\title{
La economía internacional desde una perspectiva latinoamericana*
}

\section{INTRODUCCION}

Existe un convencimiento generalizado de que los problemas actuales de la economía internacional no constituyen fenómenos de carácter coyuntural, después de los cuales volverían a recuperarse las pautas de comportamiento vigentes desde el fin de la Segunda Guerra Mundial. Esos problemas reflejan transformaciones profundas en el sistema económico internacional que, de hecho, han puesto término al período histórico comprendido entre 1945 y 1973. En éste la producción mundial creció al $5 \%$ anual, el comercio al $7 \%$, los precios aumentaron moderadamente y los desequilibrios de'l sistema monetario no afectaron la expansión sostenida de las transacciones reales. En el curso de la década de 1970 el comportamiento de la economía internacional se modificó radicalmente. El crecimiento de la producción y el comercio mundiales se redujo a cerca de la mitad del experimentado hasta 1973, los precios están subiendo a tasas cuatro o cinco veces mayores que hasta entonces, los desequilibrios de los pagos internacionales se han agudizado y provocado alteraciones sin precedentes en las paridades del dólar y de las otras monedas principales.

Las causas de estos hechos no se encuentran en la existencia de límites materiales al crecimiento en virtud de un supuesto agotamiento de recursos naturales no renovables o de los efectos contaminantes del desarrollo económico. Las visiones caclísmicas de algunos estudios de principios de la década de 1970 han sido superados por una apreciación más realista reveladora de que, en períodos históricos previsibles, no existen restricciones insalvables de falta de recursos y que la contaminación puede ser controlada a costos moderados. La explicación de los desajustes actuales del sistema económico mundial debe buscarse en otro tipo de razones. En efecto, el orden internacional gestado en la postguerra está sujeto a tensiones severas que

*Este trabajo fue presentado en la conferencia "A New Latin American in a Changing World Economy" auspiciada conjuntamente por el Programa Latinoamericano del Woodrow Wilson Center y la CEPAL, junio 25-26, 1979, y se publica con la autorización de su autor. 
pueden agruparse en tres grandes áreas: el comportamiento de las sociedades industriales avanzadas, los acontecimientos gestados en el Tercer Mundo y la confrontación entre las superpotencias.

Las sociedades industriales avanzadas enfrentan tensiones sociales crecientes y severas dificultades en la administración de la interdependencia gestada dentro del Sistema Trilateral. La inflación y el desempleo reflejan desequilibrios profundos y el debilitamiento de la capacidad, dentro de las estructuras de poder establecidas, de provocar la nueva asignación de recursos impuestos por las demandas sociales, el progreso técnico y la modificación de ciertos precios relativos en el mercado mundial (principalmente el petróleo y las manufacturas provenientes de los países de industrialización reciente). Todos los valores que fundaron el vertiginoso desarrollo de las sociedades industriales avanzadas parecen estar en tela de juicio. El papel del Estado benefactor, la función de la inversión privada, los mecanismos institucionales de toma de decisiones, el reparto del poder y del ingreso, los oligopolios sociales y la concentración del poder en las grandes empresas, todo está sujeto a cuestionamiento. Los conflictos internos de las sociedades industriales avanzadas repercuten profundamente en el sistema mundial por su gravitación decisiva en las relaciones económicas internacionales.

Los acontecimientos gestados en el Tercer Mundo también contribuyen a desestabilizar el orden económico de la postguerra. La pobreza extrema de centenares de millones de personas y la debilidad de los sistemas políticos, para transar los conflictos emergentes de todos los planos de la realidad social, multiplican en Asia, Africa y América Latina, las áreas críticas. Las tensiones gestadas en el Tercer Mundo comprometen el equilibrio de poder entre las grandes potencias, inducen tentativas de influir en el curso de los acontecimientos $y$, en definitiva, operan como nuevos factores de desestabilización del orden mundial. Por otra parte, la política de los miembros de la OpEP y la incorporación de un grupo de países de industrialización reciente al comercio internacional de manufacturas, modifican el esquema tradicional de las relaciones centro-periferia. Los países desarrollados han demostrado una notoria incapacidad de asimilar estos cambios, como lo revelan la dificultad de reaformular sus políticas energéticas y las crecientes demandas proteccionistas contra productos provenientes del Tercer Mundo.

Por último, el desarrollo tecnológico en el campo militar compromete el equilibrio entre las supexpotencias y amenaza con abrir nuevas fronteras a los gastos en armamentos. Estos gastos representan en la 
actualidad más de 400.000 millones de dólares de los cuales el $80 \%$ corresponde a los Estados Unidos, la Unión Soviética y sus aliados. Los gastos militares equivalen a'l ingreso de la mitad más pobre de la población mundial, es decir, 2.000 millones de personas ${ }^{1}$. La nueva frontera tecnológica en el campo militar compromete la preservación de la paz y es incompatible con las crecientes demandas sociales sobre los recursos disponibles en los mismos centros del poder mundial. En el pasado, los gastos militares fueron cuestionados, sobre todo desde los enfoques del Tercer Mundo, por obstaculizar un esfuerzo conjunto y solidario de la comunidad internacional para solucionar los problemas del subdesarrollo y el atraso en la mayor parte del planeta. Ahora, a esta crítica, se agregan reclamos de mayor peso político dentro de las mismas superpotencias. El sostenimiento de estructuras militares que, en la Unión Soviética compromete el 13\% del producto y en los Estados Unidos alrededor del $5 \%$, actuó en el pasado, como factor de aglutinamiento de los sistemas de poder militar y económico establecidos. Ahora, en el marco de crecientes demandas sociales y del cuestionamiento de esos sistemas de poder, el compromiso de cuantiosos recursos en el esfuerzo militar debilita la capacidad de dar respuesta a los crecientes problemas internos. Si esto es cierto, no sería extraño que se cleban encarar en un futuro no lejano programas efectivos de desarme y control internacional de armamentos. Esto implicaría, inevitablemente, la aceptación de ciertas reglas del juego tendientes a neutralizar los conflictos del Tercer Mundo desde la perspectiva de las relaciones entre los centros de poder. Sea como fuere, interesa destacar aquí que, en el nuevo cuadro de las relaciones internacionales, el enfrentamiento entre las superpotencias debilita su capacidad de enfrentar los desequilibrios emergentes de sus propias realidades internas y constituye, por lo tanto, un nuevo factor de desestabilización del orden mundial gestado en la postguerra.

Estas notas pretenden pasar rápida revista a los acontecimientos dominantes en la economf́a internacional con la intención de ubicarlos en una perspectiva adecuada de largo plazo. Si es cierto que los problemas actuales no son meramente coyunturales, entonces el único enfoque que puede arrojar alguna luz sobre esos acontecimientos es aquél que trasciende el análisis de corto plazo de las principales variables económicas: producción, demanda, comercio, movimiento de capitales, tipos de cambio, etc.

${ }^{1} \mathrm{OCDE}$. Interfutures. L'impact de l'armament sur le développement a long terme. París, 1977. 
$\therefore$ Desde una perspectiva latinoamericana, se impone un esfuerzo sistemático y persistente de comprensión de las tendencias dominantes de la economía mundial, que tanta influencia ejercen sobre la evolución de los países del área y sus relaciones recíprocas. Estas notas pretenden observar esas tendencias desde la perspectiva de un analista latinoamericano y constituyen una puesta al día de puntos de vista expresados en otras oportunidades ${ }^{2}$. El trabajo se divide en tres partes. En la primera se recuerda cómo repercutieron los acontecimientos económicos internacionales de la postguerra sobre la América Latina. En la segunda, se pretende identificar cuáles son los acontecimientos actuales más significativos en cuanto a sus repercusiones de largo plazo sobre el sistema mundial. Por último, se procura extraer algunas conclusiones sobre el impacto de esos acontecimientos sobre los países latinoamericanos.

\section{EL PERIODO 1945-1973}

\section{a) Los acontecimientos dominantes.}

En el periodo comprendido entre el fin de la Segunda Guerra Mundial y comienzos de la década de 1970 la economía internacional registró pautas de comportamiento radicalmente distintas de las vigen. tes hasta 1945. Los cambios en el orden económico internacional que afectaron más profundamente a los países latinoamericanos se refieren. a Ios siguientes campos principales:

Primero: Las tendencias del progreso técnico y la formación del Sistema Trilateral. La rapidez de las innovaciones, particularmente en las industrias químicas y metalmecánicas y en los sistemas de transportes y comunicaciones, alteraron drásticamente las estructuras preestablecidas de la producción y el comercio internacionales. Simultáneamente, el incremento del ingreso y los niveles de vida transformó sensiblemente la composición de la demanda concentrando los com.

\footnotetext{
TVéase: América Latina y los parses capitalistas desarrollados: una perspectiva del modelo centro-periferia. El Trimestre Económico. México, octubre-diciembre de 1975; La crisis del sistema monetario internacional: un enfoque estructuralista. Estudios Internacionales, Buenos Aires-Santiago de Chile, abril-junio de 1975; Precios del petróleo, "límites al crecimiento" y perspectivas de la economía internacional. Comercio Exterior, México, 1976. Estos tres ensayos aparecen en Economia Internacional Contemporánea: texto para latinoamericanos. Fondo de Cultura Económica, México, 1976. También: La crisis del Sistema Trilateral y América Latina. Comercio Exterior, México, julio de 1978.
} 
ponentes dinámicos del gasto en los sectores de desarrollo tecnológico más intenso. De este modo, el liderazgo de la producción y el comercio mundiales fue asumido por la industria manufacturera de base al mismo tiempo que la baja elasticidad-ingreso de la demanda de bienes primarios, la sustitución de productos naturales por sintéticos y otros factores deprimieron la importancia relativa de la producción de alimentos y materias primas dentro de la economía mundial. La composición del comercio internacional refleja claramente estas tendencias. En la década de $1930,2 / 3$ de las exportaciones mundiales estaba compuesto por productos primarios $y 1 / 3$ por manufacturas. Treinta años más tarde las proporciones se habian prácticamente invertido.

Bajo el liderazgo de las industrias dinámicas, la producción y el comercio internacionales crecieron a ritmos sin precedente histórico. Entre 1945 y principios de la década de 1970 la producción creció a más del $5 \%$ anual y el comercio al $8 \%$ anual. No pueden comprenderse las tendencias dominantes en el sistema internacional si no se aprecia cabalmente el impacto del cambio tecnológico y el papel asumido por las ramas dinámicas de la industria manufacturera.

Los principales protagonistas del proceso de expansión e integración de la economía mundial han sido los países industriales avanzados, plenamente capacitados para asimilar el impulso expansivo del cambio tecnológico contemporáneo. El intercambio de manufacturas entre esos países se constituyó en el sector más dinámico del comercio internacional. El intercambio pasó a realizarse principalmente entre América del Norte, Europa Occidental y Japón, es decir, dentro del Sistema Trilateral. Este Sistema es el núcleo de la economía mundial contemporánea. En la década de 1930 el intercambio entre países industriales representaba el $40 \%$ del comercio mundial; hacia 1970 la proporción se elevaba a casi el 60\%. Las principales inversiones y corrientes tecnológicas se realizan también dentro del Sistema Trilateral. Cierto es que este proceso de integración tuvo lugar principalmente dentro de grandes espacios geográficos como en América del Norte (Estados Unidos-Canadá) y Europa Occidental (la Comunidad Económica Europea) y que el Japón mantiene vínculos estrechos con el Sudeste asiático y otras regiones subdesarrolladas. Pero los vínculos comerciales entre los tres grandes componentes del Sistema Trilateral son de todas maneras muy importantes, al mismo tiempo que las inversiones recíprocas de sus grandes corporaciones y la integración de los mercados financieros revela la interdependencia creciente dentro del Sistema. Basta con recordar al respecto la impor- 
tancia de las inversiones de las corporaciones norteamericanas en Europa Occidental y la creciente corriente de inversiones europeas y japonesas hacia los Estados Unidos.

El proceso de liberación del comercio mundial se ha referido, como cabía esperar, al intercambio entre los países industriales, la drástica reducción de aranceles y barreras no arancelarias, registradas en las varias ruedas de negociaciones en el Seno del GATr en las últimas décadas, se vincula fundamentalmente al comercio de manufacturas dentro deI Sistema Trilateral. Los productos primarios y las manufacturas de especial interés para los países en desarrollo quedaron marginadas de este proceso de liberalización del comercio mundial.

Segundo: Expansión de las corporaciones transnacionales. Las nuevas tendencias del cambio tecnológico y la formación del Sistema Trilateral crearon condiciones extremadamente favorables para la expansión a escala transnacional de las grandes corporaciones industriales de los principales países, sobre todo de los Estados Unidos. Su capacidad de acumulación, dotación de tecnología y aptitud para operar a escala mundial les permitió participar activamente en la difusión de la tecnología y en la integración multinacional de los mercados y la producción. Las corporaciones jugaron un papel decisivo en la división internacional del trabajo entre los países industriales $y$, también, en el desarrollo de nuevas actividades industriales dentro de las economías periféricas. Las tendencias del progreso técnico, la formación del Sistema Trilateral y la progresiva marginación de los países en desarrollo influyeron decisivamente en el destino (por regiones y tipos de actividad) de las inversiones privadas directas. Las corporaciones concentraron progresivamente sus actividades dentro del macromercado trilateral y en las actividades manufactureras, particularmente en las industrias metalmecánicas y químicas. Dentro de la periferia, las corporaciones transnacionales desplazaron progresivamente su centro de interes desde las actividades extractivas (con la principal excepción del petróleo) y la infraestructura a la industria manufacturera, al mismo tiempo que las inversiones en los países en desarrollo perdían importancia relativa dentro de sus operaciones totales. Las corrientes financieras y la transferencia internacional de tecnología desde el fin de la Segunda Guerra Mundial estuvieron íntimamente asociados a la expansión de las corporaciones transnacionales.

Tercero: La dispersión del poder económico internacional. Al concluir la Segunda Guerra Mundial, los Estados Unidos surgieron con una abrumadora posición hegemónica dentro del mundo desa- 
mollado, Hacia 1950 el producto norteamericano representaba el $60 \%$ del producto de todo el mundo industrializado. La rápida reconstrucción de los países beligerantes europeos y de Japón yy, posteriormente, su xápido desarrollo, modificaron sustancialmente las posiciones relativas de los principales paises. En la década de 1970 la participación norteamericana en el producto del Sistema Trilateral disminuyó al $47 \%$ y tres países del Sistema (Alemania Federal, Japón y Francia) representan actualmente el $80 \%$ del producto norteamericano. Esta dispersión del poder económico entre los países integrantes del Sistema Trilateral fue acompañado por una creciente competencia internacional entre sus empresas para la venta de bienes de capital y tecnología y la realización de inversiones directas en el resto del mundo. Al mismo tiempo, la expansión de los mercados financieros internacionales, como el de eurodólares, multiplicó las fuentes de recursos disponibles y la competencia entre banqueros e intermediarios financieros que operan a escala internacional.

Cuarto: Las nuevas orientaciones dentro del Tercer Mundo y en las relaciones Norte-Sur. Las tendencias del cambio tecnológico $y$ del comercio internacional en los últimos treinta años contribuyeron a marginar a los países especializados en la producción y exportación de productos primarios. Con la excepción de los países exportadores de petróleo, las economías del Tercer Mundo han perdido rápidamente peso relativo en las transacciones económicas internacionales. Los países de Asia, Africa y América Latina que componen el Tercer Mundo generaban a fines de la década de 1940 el 30\% de las exportaciones mundiales y a principios de la de 1970 sólo el $17 \%$. La débil participación de los países en desarrollo en el clesarrollo tecnológico contemporáneo y en el proceso de industrialización debía necesariamente apartarlos de las corrientes más dinámicas de la economía internacional.

Pero, simultáneamente con esta marginación del Tercer Mundo, se produjo dentro de los países subdesarrollados, un conjunto de cambios que han modificado sustancialmente sus relaciones tradicionales con los centros de poder internacional. Fue, primero, la disolución del orden colonial. Recuérdese, al respecto, que en 1938, el $80 \%$ de la superficie terrestre y el $75 \%$ de la población mundial estaba bajo el dominio de las grandes potencias occidentales $y$, en primer lugar, de Gran Bretaña. El proceso de independencia de las viejas posesiones coloniales de Asia y Africa y, también, el desarrollo experimentado por numerosos países de esos continentes y de la América Latina, contribuyeron a crear nuevas bases económicas a las 
relaciones internacionales. Las transformaciones producidas en esos países han aumentado sensiblemente su capacidad de administrar sus propios recursos, diseñar estrategias autónomas de desarrollo y negociar sobre bases independientes con los centros del poder mundial. Las decisiones de la OPEP constituyen probablemente el ejemplo más espectacular de la modificación de las tradicionales relaciones entre el mundo industrializado y un grupo de países de la periferia. Otros ejemplos notables son los nuevos regímenes de inversión extranjera y transferencia de tecnología y las políticas de recuperación del control de recursos básicos de numerosos países del Tercer Mundo. Baste con recordar al respecto las recientes negociaciones mexicano-norteamericanas sobre la compraventa de petróleo y gas de México.

Al mismo tiempo el desarrolio industrial experimentado por un grupo de países del Tercer Mundo les ha permitido expandir sus exportaciones de manufacturas. Estas economías en desarrollo están transformando rápidamente sus relaciones tradicionales con el resto del mundo y comenzando a participar crecientemente en los rubros más dinámicos del comercio mundial.

Un aspecto significativo de esta misma cuestión es el peso de los nuevos mercados en la expansión de las exportaciones de manufacturas (sobre todo de bienes de capital) desde el Sistema Trilateral. Estos países están adquiriendo una mayor gravitación y más fuerte posición negociadora en la escena internacional.

Quinto: Al conflicto entre las superpotencias y la extensión del área de confrontación a regiones y países del Tercer Mundo. En esta breve enumeración de los principales acontecimientos entre 1945 y comienzos de la década de 1970 debe destacarse, por último la repercusión del conflicto entre los Estados Unidos y la Unión Soviética. Este actuó como factor de desestabilización de la situación política interna de numerosos países de Asia, Africa y América Latina y proyectó al plano internacional las tensiones internas de numerosas sociedades en desarrollo. Por múltiples vías, estos acontecimientos incidieron en la vinculación económica externa de esas sociedades y en sus opciones internas de modelos de desarrollo y organización social.

\section{b) La repercusión sobre América Latina.}

Las tendencias de la economía internacional entre 1945 y comienzos de la década de 1970 impactaron profundamente en la América Latina. Por una parte, declinó sustancialmente la participación de la región en el comercio mundial y su significación como destino de 
las inversiones extranjeras. Entre fines de la década de 1940 y 1970 la participación de las exportaciones latinoamericanas en las mundiales disminuyó del $11 \%$ al $5 \%$. Un ejemplo notable de esta tendencia es la evolución de la relación de la región con los Estados Unidos. Hacia 1950 el $35 \%$ del total de las importaciones norteamericanas provenía de la América Latina; en 1970 la proporción sólo ascendía al $11 \%$. Lo mismo se observa en relación a las inversiones privadas directas. Entre 1962 y 1971 la participación latinoamericana en el total de las inversiones privadas directas norteamericanas declinó del $26 \%$ al $18 \%$. La fuerte expansión de la economía internacional estimuló el crecimiento de las exportaciones latinoamericanas, pero en el marco de desequilibrios crecientes. Las importaciones de la región, pese a los avances del proceso sustitutivo tendieron a crecer más rápidamente que las exportaciones. Debido a esto $y$ al peso creciente de la deuda externa, la región enfrentó en el período un persistente desequilibrio en sus pagos internacionales. La restricción externa estimuló la industrialización al mismo tiempo que la persistencia del déficit de los pagos externos generó obstáculos severos para el desarrollo de largo plazo y el manejo de las políticas de ajuste externo y administración de la demanda. En el plano de la política internacional, la confrontación Este-Oeste se proyectó al plano interno de varias sociedades latinoamericanas. En tales casos, los conflictos internos pasaron a dirimirse en torno de confrontaciones que poco tuvieron que ver con las necesidades y las aspiraciones sociales reales.

Esto es probablemente lo más que puede decirse en un intento de generalizar, sobre el conjunto de la América Latina, el impacto producido por las tendencias del sistema mundial desde 1945 a principios de la década de 1970. La multiplicidad de situaciones nacionales existentes dentro de la región, en virtud de los distintos tamaños de los mercados internos, la diversidad de los recursos naturales y las distintas opciones de desarrollo asumidos por cada país provocaron, en cada caso, repercusiones particulares de los acontecimientos gestados en el plano internacional. En los países de mayor tamaño, la restricción externa impulsó un considerable proceso de sustitución de importaciones e industrialización. Después de las primeras etapas de la industrialización, la transformación estructural de las economías alcanzó su propia dinámica y promovió, en los casos de Brasil, México y Argentina, una considerable integración de los perfiles industriales. A partir de aquí estas economías y algunas otras de tamaño intermedio, desarrollaron una considerable capacidad de exportar manufacturas y diversificar la composición de su comercio 
exterior. En ningún caso, sin embargo, se cerró la brecha en el contenido tecnológico de las exportaciones e importaciones y la estructura del comercio exterior continúa revelando los niveles de subdesarrollo subsistentes en esos países. La capacidad de transformación interna y de vinculación a las nuevas corrientes en la economía internacional, particularmente la expansión de las corporaciones transnacionales, generó nuevos vínculos entre las realidades internas y la economía mundial. El desarrollo industrial provocó cambios notables en la estructura social y en la distribución del ingreso y del poder económico al mismo tiempo que se establecieron' con el resto del mundo relaciones mucho más complejas que en el pasado. Nada más distinto al tradicional modelo de penetración extranjera bajo el sistema de enclave, que el nuevo tipo de relaciones establecidos en torno de la participación de las corporaciones transnacionales en el desarrollo industrial. De allí que el viejo problema de la "dependencia" cambiara de naturaleza y de una versión simple, vinculada al control de ciertos recursos naturales y otros resortes del sistema económico, se pasó a un orden complejo de relaciones vinculado a la transferencia de tecnología, la coexistencia de sectores de alta productividad y densidad de capital con otros tradicionales de muy bajo producto por hombres ocupados, la vinculación de los sistemas financieros internos con los centros internacionales, el compromiso creciente de amplios sectores sociales a los nuevos modelos de desarrollo vinculados a la imitación de las pautas de consumo y las tecnologías existentes en el mundo desarrollado. En cierto sentido, puede decirse que la "dependencia" fue "nacionalizada", es decir que pasó de ser una confrontación simple entre un enclave foráneo más sus aliados internos con el resto de la sociedad, a una relación compleja en que sectores sociales muy amplios aparecen comprometidos con el estilo de desarrollo vinculado a los centros de poder internacional. De allí la complejidad actual de la situación social latinoamericana y de las opciones básicas de desarrollo que enfrentan los países del área.

La capacidad de aprovechar la dispersión del poder económico internacional en el período bajo análisis dependió también de la situación particular de cada país. Aquellos de mayor tamaño y desarrollo industrial más avanzado fueron capaces de aprovechar las nuevas condiciones vigentes en la economía mundial y diversificar las fuentes de las inversiones, la tecnología, los mercados y el financiamiento externo. En esta materia se alcanzaron algunos logros considerables como la política nuclear argentina desde comienzos de la década de 1960. La legislación y, más que la legislación, las nuevas 
prácticas negociadoras de algunos países para regular la transferencia de tecnología y la participación de las empresas extranjeras en sus economías son otros ejemplos de la mayor libertad de maniobra potencial derivada de la dispersión del poder económico internacional y de la mayor madurez interna para administrar y asignar recursos. De esa madurez interna $y$, sobre todo, de la fortaleza de las estructuras políticas internas y de su representatividad, dependió la capacidad de las sociedades latinoamericanas de enfrentar con éxito los intentos "desestabilizadores" gestados en los centros de poder internacional y en los grupos extremistas internos de izquierda y derecha. En definitiva, la situación de cada país influyó de manera decisiva la forma en que los acontecimientos internacionales del periodo 1945-1973 impactaron en su propia realidad interna.

Volviendo a un intento de generalización puede decirse que esos acontecimientos internacionales acentuaron las profundas diferencias ya existentes entre los países latinoamericanos al fin de la Segunda Guerra Mundial. La región presenta una creciente dispersión de las situaciones nacionales $y$ distintas capacidades de adaptación a los cambios gestados en el plano mundial. Desde la década de 1950, estos cambios estimularon la búsqueda de soluciones regionales para los problemas planteados desde el resto del mundo y por el propio proceso de desarrollo interno de las economías latinoamericanas. Pero multiplicidad de razones bien conocidas impidieron que la respuesta "regional" estuviera a la altura del desafío y que pudiera convertirse, en efecto, en un instrumento efectivo al servicio de cada país.

c) La crisis de 1974-75 y después.

Los acontecimientos de la economía internacional a partir de la primera mitad de la década de 1970 generaron problemas, si no nuevos, por lo menos mucho más agudos que los planteados hasta entonces. El salto inflacionario en los países desarrollados, el aumento de los precios del petróleo en 1973, la recesión de 1974-75 en los centros desarrollados y el lento repunte posterior que incluye la subsistencia de elevadas tasas de desempleo con inflación sostenida, impactaron gravemente en la economía internacional y, consecuentemente, sobre la posición de los países latinoamericanos. En la segunda mitad de la década de 1970 declinó la tasa de expansión del comercio mundial, los precios reales de muchos productos básicos tendieron a deteriorarse y las presiones proteccionistas en los países industrializados se agudizaron. Estos factores afectaron a las exportaciones 
latinoamericanas y sólo el amplio acceso al financiamiento de libre disponibilidad en los euromercados y en la banca privada internacio. nal permitió a varios países del área hacer frente a su agudizado desequilibrio externo sin restricciones severas de su nivel de actividad interno. Pero este acceso al crédito internacional implicó un fuerte aumento del endeudamiento externo y del servicio de la deuda en los balances de pago de Brasil y otros países del área. En sentido contrario, los nuevos precios del petróleo crearon en Venezuela una clisponibilidad de recursos que provocó cambios notables en el comportamiento de su economía. La inflación internacional y los desequilibrios en los pagos internacionales, incluyendo la inestabilidad del dolar y de las otras monedas principales, agudizaron las incertidumbres que enfrentan las economías latinoamericanas.

Estos problemas, que no son de mero carácter coyuntural, agravaron las tensiones internas preexistentes e indujeron respuestas en las cuales la contingencia externa sirvió a menudo de excusa para imponer las soluciones buscadas por los grupos hegemónicos internos. Lo cierto es que el espectro de respuestas frente a estos problemas incluye desde la profundización del proceso de industrialización hasta el retorno a estructuras económicas más sencillas y especializadas en torno de las ventajas comparativas estáticas. La experiencia reciente revela que los acontecimientos externos conmueven profundamente las situaciones nacionales preexistentes, pero que las respuestas al desafío externo continúan dependiendo, en lo fundamental, de las opciones internas de cada socieclad.

\section{ALGUNOS PR'OBLEMAS CENTRALES DEL ORDEN GONTEMPORANEO}

\section{a) Raices politico-sociales de los conflictos en los miembros del Sistema Trilateral.}

El prolongado proceso de expansión económica de las sociedades industriales avanzadas iniciado después de la Segunda Guerra Mundial concluyó a principios de la décacla de 1970, con la aceleración de la tasa de crecimiento de la producción y un salto brusco de la tasa de inflación. El aumento de los precios del petróleo en 1973 y el simultáneo incremento de las cotizaciones de los alimentos y materias primas agudizaron el proceso inflacionario hasta límites intolerables y provocaron un cambio drástico de la política económica de los principales países. El fracaso de la llamada política de ingresos y la tentativa de frenar la inflación mediante las políticas tradicionales de restricción de la liquidez y la clemanda, desencadenaron la recesión 
de 1974-75. La caída de la productividad durante la fase recesiva y la tendencia de arrastre del fuerte crecimiento de los salarios nominales acrecentaron el aumento de los costo unitarios del trabajo $y$, consecuentemente, de las presiones inflacionarias. El receso coincidió, así, con nuevos aumentos de la tasa de crecimiento de los precios. A partir de la recesión de 1974-75 las sociedades industriales avanzadas han sido incapaces de recuperar un crecimiento económico compatible con el pleno empleo y de reducir las presiones inflacionarias a los niveles vigentes hasta de la década de 1960. De este modo, a partir de 1974, las economías industriales enfrentan, simultáneamente, problemas de desempleo e inflación. Entre las décadas de 1960 y 1970 la tasa de crecimiento del producto declinó en $30 \%$, el desempleo más que se duplicó y el crecimiento de los precios es de 4 a 5 veces más alto.

En este contexto, las políticas económicas tradicionales se han revelado incapaces de compatibilizar el pleno empleo con la estabilidad de precios. Las políticas de signo keynesiano también lo han sido, porque el manipuleo de la demanda agregada es insuficiente para alcanzar ambos objetivos simultáneamente. Las monetaristas, porque su pretensión de "disciplinar" a las fuerzas sociales mediante el control de la oferta monetaria encubre la defensa de las posiciones de poder establecidas, incompatibles con el crecimiento futuro de largo plazo. En definitiva, la experiencia revela que las políticas ortodoxas terminan agravando el receso, la caída de la producción y el desempleo, es decir, complicando aún más la compleja situación existente en las economías desarrolladas.

Los problemas del desempleo y la inflación dentro del Sistema Trilateral han agravado aún más los problemas preexistentes en los pagos internacionales y el proceso de ajuste. Persisten superávit crónicos en Alemania y Japón y déficit en los Estados Unidos y otros países industriales menores. La flotación evitó que se reprodujeran tensiones severas en el orden monetario internacional, como los registrados en la década de 1960 y comienzos de la de 1970, pero contri* buyó sólo marginalmente a facilitar el proceso de ajuste. Las fluctuaciones cambiarias reflejan, en gran medida, las diferentes tasas de inflación, más los movimientos especulativos de capitales y no logran, por lo tanto, modificar persistentemente los precios relativos, como para restablecer el equilibrio de los pagos dentro del Sistema Trilateral. A los desajustes existentes entre las economías desarrolladas se agregó, a partir de 1973, el fuerte aumento de los precios del petróleo, la generación de una fuerte posición superavitaria en los miembros de la OPEP $y$, como contrapartida, un cuantioso déficit 
del Sistema Trilateral y de los países en desarrollo importadores de petróleo. De todos modos, estos problemas "exógenos" del mundo desarrollado no explican los problemas que enfrentan actualmente las sociedades industriales avanzadas:

En los estudios efectuados en tiempos recientes en la OECD, en la Comisión de las Comunidades Europeas, en la Gomisión Trilateral y en otros foros, parece surgir un consenso en el sentido de que las dificultades actuales del mundo industrializado no radican en insuficiencias transitorias de la demanda, rigideces de la oferta superables a corto plazo, aumentos circunstanciales de algunos precios o problemas transitorios de ajuste de los pagos internacionales. En los estudios disponibles de esas fuentes se enfatiza también el hecho de que no existen, dentro de los plazos históricos previsibles, límites al crecimiento por el agotamiento de recursos no renovables o por intolerables efectos contaminantes del desarrollo. Inclusive en el crítico problema de la energía, se admite que el esperado agotamiento de los recursos de hidrocarburos plantea la necesidad de diversificar las fuentes energéticas pero no la restricción de la oferta de energía a largo plazo. $Y$, en cuanto al problema de la contaminación del medio ambiente, está demostrado que el control de los factores contaminantes sólo compromete una proporción reducida de los recursos disponibles. Desde el punto de vista del stock tecnológico y del impacto de su aplicación al proceso económico se admite que ciertos desarrollos, como los vinculados a la industria automotriz y varias ramas de la industria química, pueden haber perdido el impulso que tuvieron en toda Ia fase expansión de la postguerra. Pero se están abriendo nuevas fronteras en el campo de la electrónica, la informática y las aplicaciones industriales de la biología, que prometen multiplicar las fuentes de crecimiento económico y la productividad. De este modo, las versiones actuales del ciclo de Kondratieff, basado en el comportamiento a largo plazo del cambio tecnológico y la acumulación de capital, no parece reflejar la naturaleza profunda de la actual desaceleración del crecimiento económico en los países desarrollados.

Como se sostiene en un informe de la OCDE el "primer desafío que enfrentan las sociedades industriales avanzadas es interno". "CCómo podrán esas sociedades adaptarse a las presiones engendradas por los cambios sociales, culturales e institucionales que se traducen en demandas diferentes sobre la distribución del producto social y en cuanto a la participación de los individuos en la producción y en las decisiones sociales? ¿Cómo superarán esas sociedades los conflictos de valor que dificultan la elaboración de las políticas gubernamentales? 
¿Serán capaces esas sociedades de engendrar Ios nuevos valores, los nuevos comportamientos y las nuevas instituciones capaces de responder a los problemas de mañana?"3. Estos son los interrogantes y los conflictos que encaran hoy en día las sociedades industriales avanzadas y su origen parece radicar en el mismo proceso de transformación experimentado desde el fin de la Segunda Guerra Mundial. Según un informe de la CEE: "Cada progreso del bienestar material y de la educación refuerza el deseo de la gente de participar en las decisiones que les conciernen. Esta exigencia es rechazada por la tendencia simultánea a la concentración y al gigantismo del poder económico y a la burocratización del poder político. En la base de estos conflictos existe una insatisfacción más profunda, de naturaleza moral, que cuestiona los resuitados y la significación del clesarrollo debido a sus efectos ecológicos; su costo humano, su ausencia de finalidad más allá de él mismo. De allí la desorientación de conciencias, un sentimiento de inutilidad e irracionalidad, fuentes de la frustración y la violencia"4.

Las sociedades industriales avanzadas enfrentan un proceso de "esclerosis institucional" vinculado a la formación de "oligopolios sociales" en torno de las concentraciones de poder económico en las grandes empresas, los sindicatos y el Estado. Esta situación ha debilitado la notable capacidad de aclaptabilidad ante el cambio que aquellas sociedades manifestaron durante todo el prolongado proceso de expansión de la postguerra. "Durante el último cuarto de siglo, las sociedades industriales avanzadas mostraron una marcada adaptabilidad estructural para enfrentar la transformación de la producción, las migraciones entre sectores, dentro de sectores y entre regiones, las tecnologías empleadas, los vínculos entre empresas y grupos, la internacionalización de la producción y las características de la oferta y demanda de trabajo" ". Esta aclaptabilidad al cambio ha quedado comprometida por la "esclerosis institucional", por la resistencia de los grupos de poder a las transformaciones que los afectan y por el cuestionamiento de amplios sectores sociales a los valores que enmarcaron el proceso de desarrollo desde 1945 en adelante.

La sociedad postindustrial ha engendrado nuevos valores entre los cuales se destacan las demandas por la igualdad; la defensa del medio ambiente; la preferencia por la seguridad, el hedonismo, el arraigo a los medios locales y la nueva valorización de la familia como

${ }^{\mathrm{O} O C D E}$. Interfutures. Projet de Rapport final. Paris, 1978.

${ }^{4}$ CEE. Un projet pour l'Europe. Bruselas, 1978.

OCCDE. Interfutures. Draft final report. Part II. París, 1978. 
fuente de apoyo efectivo; el rechazo a los manipuladores del poder y de la tiranía de las decisiones de corto plazo ${ }^{6}$. Los nuevos valores llegan inclusive a cuestionar la legitimidad de la meritocracia fundada en la educación porque ésta se basa en un orclen social injusto, en la "Iotería genética" y en la transmisión hereditaria de los patrones culturales?.

Desde estas perspectivas, la conclusión es evidente: "El problema inflación-desempleo es en efecto la forma específica que asume el conflicto social sobre el plano económico en un período de rigidez creciente de las estructuras sociales"8. Estos fenómenos contribuyen a explicar el debilitamiento de la inversión privada y su insuficiente respuesta a las ampliaciones necesarias de la capacidad productiva, la transformación de la composición de la oferta y la generación de nuevos empleos. Las empresas enfrentan nuevas demandas de inversión para ampliar la capacidad productiva, sustituir mano de obra y. compensar el aumento de los costos de la energía y de las normas para la preservación del medio ambiente. Pero la modificación permanente de los precios relativos y las crecientes presiones sociales han modificado las reglas del juego dentro de las cuales la inversión privada lideró la expansión de la producción y el cambio tecnológico en las últimas décadas. Lo mismo puede decirse con respecto al papel del.Estado en la regulación cle la demanda agregada y la expansión del gasto y la inversión públicas. El Estado está siendo cuestionado como una fuente de concentración de poder burocrático opuesto a los nuevos valores al mismo tiempo que las nuevas demandas sociales imponen; inevitablemente, una expansión de las prestaciones del sector público. Uno de los dilemas centrales que enfrentan hoy las sociedades avanzadas radica en cómo compatibilizar estas demandas con la resistencia al aumento de la presión tributaria y la necesaria eficacia en la asignación global de los recursos disponibles.

Todo parece indicar que estas sociedades enfrentan hoy agudas crisis internas y que la solución de sus problemas económicos actuales no podrán darse fuera del marco de profundos cambios político-institucionales. Esta crisis interna de las sociedades avanzadas se proyecta a la administración de su interdependencia dentro del Sistema Trilateral. El progresivo debilitamiento de la hegemonía norteamericana y la dispersión del poder dentro del mundo industrializado ha desplazado

'OCDE. Interfutures. La dynamique des sociétés industrielles avancées. París, 1977. TTbid.

${ }^{8}$ Un projet pour l'Europe, op. cit. 
el centro de decisiones desde la potencia anteriormente hegemónica del grupo de países centrales dentro del Sistema Trilateral. Las tensiones internas de los países desarrollados repercuten en sus relaciones recíprocas y los desequilibrios de éstas agudizan, a su vez, las tensiones internas que aquéllos soportan. Por ejemplo la inestabilidad de las cotizaciones de las principales monedas refleja los desequilibrios en los pagos internacionales y hace más difícil la ejecución de las políticas antiinflacionarias nacionales y la administración de la demanda interna. A su vez, la persistencia de distintos ritmos inflacionarios y de niveles de actividad dificultan el proceso de ajuste de los pagos internacionales.

Lo menos que puede decirse es que no se advierten respuestas claras de los principales países frente a la dimensión de los problemas que enfrentan. EI desarrollo es cuestionado y, además, frenado por las políticas estabilizadoras convencionales. Pero, al mismo tiempo, el freno al desarrollo dificulta aún más la adaptabilidad al cambio de las estructuras económicas y sociales. Uno de los grandes méritos históricos del capitalismo en los países centrales radica en que es un sistema indisolublemente ligado al crecimiento. Su propia capacidad de generación de tecnología y ahorro impone la permanente expansión de la oferta y la demanda globales. Si no lo logra, sus tensiones internas alcanzan niveles intolerables.

Es interesante observar dentro del debate actual de los países: avanzados el desarrollo de dos líneas de pensamiento dominantes. Una, caracterizada como defensiva, que pretende aceptar una baja de la tasa de crecimiento a largo plazo, acomodar la reducida demanda de empleo mediante una disminución de la tasa de participación y de las horas de trabajo y compensar los desequilibrios sectoriales y regionales con medidas compensatorias ad hoc. Parece poco probable que esta línea de pensamiento logre evitar la acumulación de tensiones. Una de sus manifestaciones es el proteccionismo frente a Ia competencia emergente desde algunos países del Tercer Mundo y aun desde dentro del mismo Sistema Trilateral, como en el caso del Japón. Sin embargo, el proteccionismo posterga la necesidad del reajuste pero no la elimina. Compromete, por otra parte, una de las reglas básicas del proceso de transnacionalización del sistema internacional en la postguerra, incluyendo la expansión de las grandes corporaciones.

La segunda línea, caracterizada como ofensiva, pretende asumir el clesafío del cambio, recuperar una fuerte tasa de crecimiento y promover las transformaciones político-institucionales que liberen 
las fuerzas del crecimiento. EI conflicto político-social en las sociedades industriales avanzadas se expresa-inevitablemente en términos de distintas estrategias económicas que no pasan, necesariamente, por las categorias tradicionales del pensamiento político de izquierda y derecha. En efecto, pueden encontrarse estrategias ofensivas y defensivas en ambos campos políticos tradicionales.

Como se sostiene en los informes citados, los "nuevos valores" no son necesariamente incompatibles con el desarrollo económico. Plantean, eso sí, la necesidad de nuevas reglas del juego dentro de las cuales debe registrarse la acumulación de capital, la asimilación del cambio tecnológico y la distribución del producto social. La capacidad de las sociedades industriales avanzadas de compatibilizar esos "nuevos valores" con el desarrollo es uno de los mayores interrogantes que se plantean hoy en el sistema internacional.

El problema central de los países industriales es, actualmente, aumentar la productividad y, simultáneamente, lograr un sostenido crecimiento de la demanda, con el pleno empleo y la estabilidad de precios. Se trata, en cierto sentido, de un círculo vicioso. El desempleo y la inflación desalientan la acumulación de capital, la penetración del cambio tecnológico, la división internacional del trabajo y, consecuentemente, el incremento de la productividad. A su vez, el lento crecimiento de la productividad, del ingreso real y la demanda acrecientan las tensiones sociales que fomentan la puja por la distribución del ingreso y la inflación. Estos problemas no pueden ser resueltos desde fuera de las mismas economías desarrolladas. Por ejemplo, el redespliegue de las actividades de menor densidad tecnológica hacia los países en desarrollo constituye, desde la perspectiva de los centros, una vía idónea para aumentar la productividad y el ingreso real. Pero esto requiere, como condición previa, que las economías desarrolladas recuperen niveles satisfactorios de crecimiento y empleo. De otro modo, como lo revela la experiencia, las presiones proteccionistas imponen severas restricciones a la expansión de las importaciones desde los países en desarrollo. Lo mismo puede decirse de la posibilidad de aumentar radicalmente la transferencia de recursos hacia el Tercer Mundo. Esto expandiría las exportaciones y la demanda en los países industriales pero, al mismo tiempo, generaría una mayor corriente importadora desde los países en desarrollo. En las condiciones contemporáneas, la expansión del comercio internacional y de la transferencia de recursos descansa fundamentalmente en la solución de los problemas internos que actualmente enfrentan las economías industriales. 


\section{b) El cambio tecnológico.}

Se sostiene en un informe de la ocDE: "Una nueva generación de ramas industriales está desplazando a aquellas que impulsaron el desarrollo manufacturero de la postguerra. Dentro de esa nueva generación el sector más importante es el llamado 'complejo electrónico' que abarca la automatización, la informática y las telecomunicaciones. Ese 'complejo' afectará de manera creciente la naturaleza misma de la actividad económica tanto en la producción de bienes y servicios como en los patrones de consumo y en la función de las comunicaciones"9. La automatización de los procesos productivos y la integración creciente entre la industria electrónica y la producción de maquinarias y equipos excede el impacto tradicional de la mecanización sobre la productividad. El "complejo electrónico" actúa sobre la productiridad desde varios frentes simultáneos: el ahorro de trabajo, la adaptabilidad de la capacidad productiva a los cambios de tipos de productos y ritmos de fabricación, la mejora de la calidad y la reducción de los costos de control, la administración de operaciones cada vez más complejas a través del control automático de los procesos, la modificación de las condiciones de trabajo y del medio ambiente y la redistribución internacional de la producción a través de la factibilidad de fragmentar las distintas etapas del proceso productivo. Según el informe citado "el complejo electrónico constituirá en el próximo cuarto de siglo el polo principal alrededor del cual se reorganizarán las estructuras productivas de las socieclades industriales avanzadas".

Desde el fin de la Segunda Guerra Mundial la especialización intraindustrial, al nivel de productos dentro de las mismas ramas industriales, constituyó el proceso dominante de la expansión del comercio de manufacturas entre las economías integrantes del Sistema Trilateral. El desarrollo del "complejo electrónico" ampliará las bases de la especialización intraindustrial a escala internacional. Actualmente, los países desarrollados generan alrededor del $85 \%$ del valor agxegado por la industria electrónica y consumen cerca del $80 \%$ del total de bienes producidos por el sector. La mayoría del intercambio y de la especialización intraindustrial de la producción de componentes, bienes de capital automatizados y productos de consumo durable se realiza entre las mismas economías desarrolladas. Las principales inversiones privadas directas en el sector se han realizado también entre países industriales. En 1970 el 50\% del mercado europeo de semiconductores y el $72 \%$ de circuitos integrados era abastecido con producción de las corpora-

๑OCDE. Interfutures. Projet de repport final. Cinquième partis. Paris, 1978. 
ciones norteamericanas y sus filiales en Europa. Sin embargo, varios países en desarrollo del Sudeste Asiático (Corea, Taiwan, Hong-Kong, Singapur) y de América Latina (Brasil y México) han atraído inversiones considerables de corporaciones transnacionales, sobre todo de los Estados Unidos, Japón y Alemania.

EI papel previsto para el complejo electrónico en el orden internacional plantea desafíos importantes a la formulación de la estrategia económica de cada país y no sólo de los menos desarrollados. Los Estados Unidos conservan una clara posición hegemónica en la tecnología de componentes y circuitos integrados. En 1974 el $72 \%$ de las inversiones de firmas transnacionales en el sector de semiconductợres en los países en desarrollo corresponde a empresas norteamericanas. El Japón mantiene una firme política de contestación del predominio de los Estados Unidos y es el país industrializado que sostiene la política más coherente de desarrollo y componentes, bienes de capital y procesos automáticos. Con la excepción de Alemania, el resto de Europa mantiene una actitud más pasiva en esta materia siguiendo detrás del liderazgo norteamericano.

Para los países en desarrollo, sobre todo aquellos con mayores posibilidades de integrar sus sistemas manufactureros, la expansión del complejo electrónico plantea problemas decisivos en la definición de las estrategias tecnológicas y de participación en los sectores industriales de punta. Los principales interrogantes se plantean en relación a la producción de las ramas más complejas del sector electrónico y a la participación de las empresas nacionales y extranjeras en ese desarrollo. En los productos de consumo de masa y de tecnologías normalizadas con alto empleo de mano de obra se ha experimentado ya un considerable avance en numerosos países del Tercer Mundo. En la nueva frontera, por ejemplo, de microprocesadores para la automatización de los procesos industriales, el acceso será más difícil y fuertemente influenciado por la participación de las corporaciones transnacionales.

Otro campo de problemas emergente de las nuevas tendencias del desarrollo tecnológico e industrial se refiere al impacto del procesamiento de informaciones y de las comunicaciones sobre el funcionamiento de los mercados. La difusión de la información a escala mundial y la creciente comunicación entre los mercados y las con. diciones de oferta y demanda en múltiples localizaciones amplían el número de empresas capaces de competir en el mercado mundial. Desde esta perspectiva, el desarrollo del complejo electrónico está debilitando la concentración del poder económico en múltiples mer- 
cados, a los cuales el acceso estaba tradicionalmente restringido a las grandes corporaciones transnacionales.

Otro impacto del desarrollo tecnológico que provocará cambios significativos en la organización de la economía mundial se vincula a los límites al gigantismo y a las economías de escala. En múltiples sectores se observa el desarrollo de tecnologías "ligeras" aptas para su desarrollo en empresas medianas y pequeñas que pueden utilizar Ios factores con mayor eficacia que las grandes empresas. En tales casos se observan, en efecto, deseconomías de escala por la menor adaptabilidad de las grandes unidades productivas a las nuevas condiciones de la producción. El gigantismo tropieza así con restricciones tecnológicas que se suman a la contestación creciente a las grandes concentraciones de poder económico.

\section{c) Dispersión del poder en la economia mundial.}

Se recordó anteriormente que la rápida expansión económica de Alemania, Japón y otros países industriales contribuyeron a debilitar la posición hegemónica de los Estados Unidos dentro del Sistema Trilateral y la economía mundial. El surgimiento de varios países en desarrollo de industrialización reciente contribuye a ampliar el número cle economías nacionales que participan activamente en las relaciones económicas internacionales. Recuérdense, por ejemplo, la exitosa participación de empresas sudcoreanas en grandes contratos de construcción en los países petroleros del Medio Oriente y los avances brasileños en la venta de servicios de ingeniería y bienes de capital en Africa y otras áreas. La presencia de la Unión Soviética y de las economías de Europa Oriental en algunos mercados opera en el mismo sentido.

La expansión de la liquidez internacional, el desarrollo de los mercados de euromonedas y la internacionalización de la banca de numerosos países, incluyendo algunos integrantes del Tercer Mundo, ha debilitado la disciplina financiera tradicionalmente ejercida por el Fondo Monetario Internacional. La búsqueda del negocio excede los criterios tradicionales de la ortodoxia financiera y esto ha permitido a numerosos países un amplio acceso, sin ningún tipo de condicionamiento, a nuevas fuentes de recursos, inclusive para el financiamiento de desequilibrios de balance de pagos. Las restricciones tradicionales impuestas para los recursos con este destino por el FMI, las ataduras a las fuentes de suministros de los créditos de organismos internacionales, los créditos de proveedores y otros fondos de uso 
condicionado han perdido importancia relativa frente a los financiamientos de libre disponibilidad.

Todos estos factores implican una dispersión del poder económico internacional y la multiplicación de las fuentes de abastecimiento de bienes de capital, tecnologías y financiamiento. El número de empresas que participan en los principales mercados se ha acrecentado y la competencia entre ellas es cada vez mayor. El fenómeno de concentración oligopólica en numerosas industrias dentro de los Estados Unidos y otros países industriales ha sido acompañado por el aumento del número de empresas que participan en las operaciones internacionales. Un ejemplo importante es el sector automotriz. Cerca dèl $90 \%$ de la producción automotriz de los principales países industriales (Estados Unidos, Canadá, Japón, Francia, Alemania Federal, Italia y el Reino (Unido) está concentrado en las tres principales firmas de cada país. Sin embargo, a escala mundial y aun dentro del mercado interno de cada uno de esos países, el sector automotriz es competitivo. Con muy pocas excepciones, en los principales mercados internacionales de bienes de capital, tecnologías y productos intermedios y de uso final compiten un gran número de firmas. Este proceso de dispersión del poder económico internacional es réforzado por otras tendencias que están contribuyendo a debilitar el papel de las grandes corporaciones transnacionales en el mercado mundial.

Desde 1945 en adelante, Ia expansión de las corporaciones de los Estados Unidos :y otros países industriales se vio favorecida por un conjunto de factores. Las economías de escala estimularon el proceso de concentración y de aglomeración simultáneamente con la proyección de las actividades de las grandes empresas a escala mundial. La concentración de los gastos de investigación y desarrollo experimental en esas empresas contribuyó a acentuar aún más su liderazgo tecnológico. La capacidad organizativa para operar en grandes mercados y en el plano internacional contribuyó también a favorecer la expansión de las corporaciones transnacionales. El control de la información y la capacidad de aprovecharla en una sola estructura de decision, que opera a escala transnacional, fortaleció aún más el desarrollo de las corporaciones y el proceso de transnacionalización. El potencial financiero y de acumulación de esas firmas contribuyó a configurar el cuadro excepcionalmente favorable a su expansión desde 1945 en adelante. No es extraño, pues, que la especialización intraindustrial a nivel de productos, que caracterizó el desarrollo del intercambio dentro del Sistema Trilateral, haya contado entre sus principales partícipes a las corporaciones transnacionales. Se estima que, 
hacia 1970, el $25 \%$ del comercio mundial consistía en un intercambio intra-firmas.

Estas tendencias estimularon la formulación de algunas visiones prospectivas que concebian la organización de la economía mundial del futuro en torno de un reducido grupo de grandes empresas transnacionales. La concentración del poder económico constitúa, conforme a esas perspectivas, el cauce lógico para la organización eficiente del sistema mundial, por encima de las soberanias de los estados nacionales.

Sin embargo, los factores extremadamente favorables a la expansión de las corporaciones transnacionales comenzaron a ser progresivamente erosionados. Al respecto, cabe destacar los siguientes hechos principales:

Primero: El gigantismo tiende a producir deseconomías de escala por la emergencia de una "esclerosis" burocrática, típica de las grandes organizaciones, que debilita la adaptabilidad de la firma a los cambios de la tecnología y en las condiciones de los mercados.

Segundo: El cambio tecnológico en múítiples sectores se adapta más a las organizaciones medianas y pequeñas que a los gigantes transnacionales. En zumerosos sectores se advierte un desplazamiento desde tecnologías capital-intensivas a un uso mayor de personal técnico y obreros especializados en el marco de pequeñas y medianas empresas. Esto es particularmente evidente en muchas ramas productoras de maquinarias y equipos y en la industria electrónica. Se trata de las llamadas "tecnologías ligeras" con un uso intensivo de talento susceptible de una organización más eficiente en unidades menores que las características de las grandes corporaciones.

Tercero: El desarrollo de nuevos métodos de administración y difusión de la información a escala transnacional que permite un amplio acceso al conocimiento sobre las condiciones de producción y oferta vigentes en múltiples mercados, las tecnologías disponibles, las plazas financieras y otros datos esenciales. Este tipo de información, anteriormente reservado a las grandes corporaciones, está hoy disponible para multiplicidad de empresas medianas y pequeñas interesadas en operar a escala internacional.

Guarto: La resistencia política creciente en los principales países industriales a las concentraciones del poder económico y burocrático y la difusión de nuevas pautas de organización de las empresas en torno de la llamada "democracia industrial". Este factor tiende a modificar las pautas de comportamiento de las grandes firmas y a reorientar su capacidad expansiva hacia fines distintos de los tradicionales. 
Quinto: La multiplicación y diversificación de las fuentes de financiamiento accesible a las pequeñas y medianas empresas. Esto debilita el mayor poder relativo que tradicionalmente tuvieron las corporaciones transnacionales a partir de su capacidad de acumulación interna y de acceso al crédito internacional.

Sexto: El fortalecimiento de los estados nacionales en los mismos países desarrollados y en el Tercer Mundo, con vistas a ejercer un control político más efectivo de las grandes concentraciones de poder económico y compatibilizar su existencia con demandas sociales de participación, la defensa del consumidor y del medio ambiente. En numerosos países del Tercer Mundo este proceso se expresa en términos de regulación de la participación de las corporaciones transnacionales en el desarrollo interno, el comercio internacional, la transferencia de tecnología y la posición competitiva frente a las empresas nacionales públicas y privadas.

Estas tendencias están provocando cambios significativos en la organización de la producción al nivel de la firma y en las relaciones económicas internacionales. Las pequeñas y medianas empresas están participando activamente en múltiples mercados, inclusive en sectores de alta tecnología. Recuérdense, por ejemplo, los complejos industriales norteamericanos en la región de Boston y en California y el desarrollo de la industria mecánica sueca. Estas firmas están teniendo una actividad mucho más intensa en el mercado internacional de bienes, servicios, capacidad gerencial y organizativa de unidades productivas. Los acuerdos de coproducción, los joint-ventures, la venta de servicios gerenciales, el suministro de tecnología, son algunos de los ejemplos de las nuevas formas de negocios internacionales en que participan empresas medianas y pequeñas de los países industriales y del Tercer Mundo. Estos procesos están induciendo cambios significativos en las pautas tradicionales de comportamiento de las grandes corporaciones y una mayor adaptabilidad a las nuevas exigencias de los negocios internacionales.

Estos hechos inducen a pensar que el proceso expansivo de las corporaciones transnacionales, dentro de los moldes dominantes desde 1945, esté tocando a su fin. De este modo, la convergencia de esta tendencia con las apuntadas anteriormente, contribuye a configurar una dispersión del poder económico internacional que constituye uno de los procesos más importantes de la economía internacional contemporánea.

La dispersión del poder dentro de la economía internacional contemporánea se aprecia claramente si se compara la situación actual con la vigente hasta la Segunda Guerra Mundial y con la que aún 
prevalece en algunos sectores "tradicionales". En los mercados de minerales (cobre, estaño, bauxita y otros), en la producción y comercialización de petróleo, en la comercialización de las carnes y en otras áreas predominaron tradicionalmente combinaciones oligopólicas que regulaban las condiciones de produción, los precios y la distribución del ingreso entre los agentes de la producción y el sector público. Dada la gravitación creciente del comercio de manufacturas y de las inversiones en la industria dentro de las transacciones internacionales de postguerra, las concentraciones oligopólicas son menos frecuentes y el poder económico está más disperso. En las condiciones actuales prevalecen aún condiciones oligopólicas en los mercados de ciertos productos básicos, pero las políticas de los miembros de la OPEP y la nacionalización de la explotación de los recursos naturales en varios países en desarrollo han contribuido a modificar las situaciones prevalecientes hasta no hace mucho tiempo. En otros términos, la concentración del poder económico, el control de las plazas financieras y la asimetría del poder negociador, eran muchos más marcados dentro del modelo tradicional centro-periferia que en las condiciones contemporáneas.

\section{d) Transformaciones en el Tercer Mundo.}

Las transformaciones dentro de los países del Tercer Mundo se han convertido en un factor de desestabilización del viejo orden económico internacional $y$ de cambio en las relaciones internacionales. Históricamente, la periferia de los países centrales jugó un papel pasivo en los acontecimientos internacionales: se vinculaba al orden mundial a partir de acontecimientos $y$ tendencias gestadas en los centros de poder mundial. Los vínculos de la mayor parte de Asia, de Africa y la América Latina con el mundo desarrollado se plasmaron a partir de las orientaciones imperantes en este último. Desde el fin de la Segunda Guerra Mundial la situación se ha transformado profundamente.

El análisis de la gravitación del Tercer Mundo en la formación de un nuevo orden mundial requiere explorar dos cuestiones previas. Primero, la dispersión existente dentro del mundo en desarrollo. Segundo, la iniciativa asumida por el Tercer Mundo en el comportamiento de las relaciones internacionales.

Las diferencias existentes entre los países integrantes del Tercer MIundo son mucho mayores que las imperantes dentro del Sistema Trilateral. En éste la dispersión del ingreso por habitante va de 1 a 3. En el Tercer Mundo de $I$ a 27. Las diferencias en términos 
de población, dimensión territorial y dotación de recursos naturales son también gigantescas. Las diversidades culturales, raciales y religiosas contribuyen a configurar un cuadro aún más heterogéneo. $\mathrm{La}$ distribución del ingreso entre sectores sociales y los niveles de pobreza y bienestar registran también profundas diferencias entre los países componentes del Tercer Mundo. Los sistemas políticos y sociales y su aptitud de encauzar los procesos de cambio y desarrollo económico difieren también radicalmente. La viabilidad de los modelos de desarrollo económico y el tipo de vínculos con los centros de poder y cll resto del mundo registran también enormes diferencias. El cuadro es, de hecho, tan diverso que la misma categoría de Tercer Mundo está perdiendo capacidad explicativa del papel que los países que lo integran están jugando en el comportamiento del sistema mundial.

La segunda consideración previa se refiere al hecho ya apuntado que los cambios en las relaciones de los países en desarrollo con el resto del mundo se vienen produciendo a partir de acontecimientos gestados en la misma periferia. Por ejemplo, la política de precios del petróleo seguida desde 1973 por los países miembros de la OPEP, ha provocado un impacto profundo en la economía internacional. No tanto como pretenden algunos voceros del mundo desarrollado pero, sin duda, importante. E1 surgimiento de un grupo de países de industrialización reciente, como participantes activos en el comercio internacional de manufacturas, es otro proceso, gestado en la periferia, que está provocando cambios sensibles en el comportamiento de los mercados internacionales. Por último, las tensiones políticas de algunas sociedades del Tercer Mundo, como la reciente experiencia del Irán, contribuye también a desestabilizar el viejo orden de las relaciones internacionales.

El grupo de los países de industrialización reciente abarca un reducido número de países (Brasil, México, Argentina, Corea del Sur y Taiwan) ${ }^{10}$. Otros países que registran avances importantes en

${ }^{10} \mathrm{La}$ inclusión de Argentina requiere una aclaración. Ese pais ha sido hasta tiempos recientes el país más industrializado y de más alto ingreso por habitante dentro del grupo. Ha sido también uno de los principales exportadores de manufacturas dentro de los llamados NICs (new industrialized countries). La insistencia de Argentina, en la segunda mitad de la década de 1970 de bloquear los caminos de su desarrollo nacional, agrava su lento desarrollo en el largo plazo y abre una incógnita en cuanto a su ubicación en el orden mundial del futuro. En cuanto a Hong-Kong y Singapur, dos ciudades-estados de activa participación en el comercio mundial de manufacturas, se trata de dos ciudades-estados más comparables a las ciudades italianas y del Mar del Norte en el Renacimiento que ubicables en el marco de la experiencia texcermundista. 
su industrialización y capacidad competitiva internacional probablemente se incorporarán a mediano plazo en ese grupo de economías de industrialización reciente. Ejemplos de este tipo de situación se encuentra América Latina (p. ej. Venezuela y Colombia), Africa (Egipto, Nigeria y Argelia) y en Asia (Malasia y Filipinas). El grupo de países en vías de industrialización viene jugando un papel importante en las relaciones económicas internacionales. Aportan actualmente alrededor del $10 \%$ de las exportaciones mundiales de manufacturas y tienen cierta gravitación en el comercio de semimanufacturas (textiles, hierro y acero, pulpa y papel), productos metalmecánicos (maquinaria, material de transporte y telecomunicaciones, equipos eléctronicos) y bienes de consumo final (vestuario, calzado, juguetes). La significación creciente de estos países en el comercio mundial de manufacturas se apoya en la formación de ventajas comparativas dinámicas gestadas en el mismo proceso de industrialización. La calificación de los recursos humanos, el cambio de los precios relativos de los factores, la elevación de los niveles tecnológicos y de la capacidad de gestión, contribuyen a modificar permanentemente las ventajas comparativas y la ubicación de esos países en los mercados internacionales. Es interesante observar que la amplia gama de productos exportados por este grupo de países se ubica dentro de la llamada "especialización intraindustrial". Esto es, en el intercambio de productos dentro de las mismas ramas industriales. Este proceso se apoya en las ventajas comparativas que emergen de la distinta intensidad en el uso de factores dentro de los productos fabricados por cada rama manufacturera. La especialización intraindustrial es la forma especifica de división internacional del trabajo dentro del Sistema Trilateral. Ello ha compatibilizado la rápida expansión del intercambio con la integración creciente de las estructuras industriales dentro de las economías desarrolladas. Desde la perspectiva de las economías de industrialización reciente este tipo de especialización en el marco del sistema internacional permite, también, compatibilizar la apertura externa con un desarrollo interno integrado, complejo y de crecientes niveles tecnológicos.

Los países en consideración están jugando también un papel importante como mercado de los países desarrollados. En el periodo 1955-1973 al 30\% del incremento de las exportaciones de manufactu. ras descle los países miembros del Sistema Trilateral se destinó al resto del mundo, sobre todo, a miembros de la 'OPEP y a los países en desarrollo de industrialización reciente ${ }^{11}$. Las corporaciones trans-

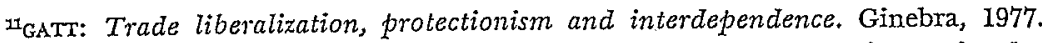
En el mismo perfodo, el intercambio dentro de los grandes espacios regionales 
nacionales juegan un papel importante en la industrialización y expansión de las exportaciones cle los "NICs", sobre todo en industrias tecnológicamente avanzadas como la electrónica y las metalmecánicas. El "redespliegue" de ciertas actividades desde los centros se refiere predominantemente a los países de industrialización reciente en el marco de una división internacional del trabajo, a nivel de la firma, para aprovechar, a escala internacional, las diferencias en los precios relativos de los factores. Sin embargo, la expansión de las exportaciones de manufacturas desde ese grupo de países se explica en gran medida por la actividad de firmas nacionales. Ejemplos en este sentido son las exportaciones argentinas de plantas llave en mano y de máquinas-herramientas. Los países de industrialización reciente son también activos tomadores de recursos en los mercados financieros internacionales conforme lo revela la dimensión de los eurocréditos con ese destino.

Las respuestas del Sistema 'Trilateral a los desafíos gestados en la periferia han sido eminentemente pasivas. Los llamados programas de ayuda externa, incluyendo el régimen de preferencias arancelaria, compromete una ínfima proporción de recursos de los países centrales y han estado tradicionalmente vinculados a promover la influencia política y los intereses económicos de los países "donantes" antes que las necesidades reales del mundo en desarrollo. En relación a la dimensión de los problemas de la pobreza extrema que afecta a alrededor de 1.000 millones de personas en el Tercer Mundo, la ayuda externa ha sido, en verdad, muy pequeña. Frente al aumento de los precios del petróleo y el cambio radical que éste impone en los precios relativos de la energía y en las fuentes alternativas de abastecimiento, los países desarrollados y, sobre todo los Estados Unidos, no han Iogrado aún definir nuevas estrategias de producción y consumo de energía. El desafío proveniente desde los países de industrialización reciente ha tenido como resultado, en el marco de las condiciones de lento

de América del Norte (Canadá y Estados Unidos) y Europa Occidental representó el $52 \%$ del incremento del intercambio y el comercio entre América del Norte, Europa Occidental y Japón el $19 \%$. Es interesante observar que la expansión comercial dentro del Sistema Trilateral se expresa, fundamentalmente, a partir de la integración regional. Sin embargo, como ya se recordó, las relaciones entre los tres polos del Sistema Trilateral son muy intensas en las areas de inversiones privadas directas (por ejemplo de corporaciones norteamericanas en Europa Occidental), en las corrientes financieras (mercados de euromonedas) y tecnología. La interdependencia dentro del Sistema Trilateral abarca, ast, el conjunto de las relaciones económicas de sus integrantes. 
crecimiento y alto desempleo vigente en los centros, un fortalecimiento de las presiones proteccionistas. El Sistema Trilateral ha demostrado hasta ahora una muy escasa capacidad de adaptación a las transformaciones impuestas desde el Tercer Mundo. Las crisis políticas en varios países africanos, Irán y otras partes, ha revelado la impotencia de las tradicionales políticas intervencionistas y agudizado las tensiones entre las superpotencias.

Enfrentado a sus propias dificultades internas, el mundo desarrollado revela una notoria incapacidad de asimilar los cambios gestados en el Tercer Mundo. No es previsible que la situación cambie a corto y mediano plazo. Es probable que los países centrales sigan reaccionanclo frente a esos cambios sin asumir un liderazgo que permita orientar las relaciones internacionales hacia la formación de un nuevo orden económico mundial viable. En tales condiciones, no es desatinado suponer que los acontecimientos gestados "autónomamente" en la periferia continuarán impactando en el orden mundial y generando nuevos factores de desequilibrio dentro del mundo desarrollado. En todo caso, la participación de los centros de poder en la gestación de esos acontecimientos seguirá operando más por la vía indirecta dél comportamiento de los mercados o las corporaciones transnacionales que por el liderazgo de la política de los estados.

En este contexto pueden identificarse algunas tendencias posibles en la evolución del Tercer Mundo y en su inserción dentro del sistema mundial. En primer lugar, siguen ampliándose las diferencias existentes entre los países subdesarrollados. Las economías de industrialización reciente y otro pequeño grupo de países en proceso de industrialización probablemente superarán, antes de fin de siglo, la barrera del subdesarrollo y se incorporarán como participantes activos en las corrientes más dinámicas del comercio y otras transacciones internacionales. En función de sus propias políticas internas estos países estarán en condiciones de superar los problemas más agudos de la po. breza dentro de sus propias fronteras. Sin embargo, varios de estos países no están a salvo de severas tensiones de sus sistemas políticos, que pueden frustrar el proceso de desarrollo y transformación de su inserción internacional. El problema de la pobreza extrema continuará concentrado en varios países asiáticos (India, Pakistán, Bangladesh) y en Africa negra al sur del Sahara. La dimensión del atraso en estos países es de tal magnitud que difícilmente podrán superar en los plazos previsibles sus niveles actuales de subdesarrollo y las disparidades de ingresos internos que los caracterizan. Además, muchos países de pequeña dimensión y escasos recursos constituyen ejemplos 
de sociedades no viables en el marco de sus propios límites nacionales. Los países petroleros del Medio Oriente ha aicanzado una fuerte gravitación internacional por su control de un recurso estratégico y sus fuertes excedentes financieros. Su papel dentro del orden económico internacional dependerá en gran medida de la evolución de la situación energética mundial, incluyendo el desarrollo de fuentes alternativas al petróleo, su propia capacidad de reinversión de los excedentes petroleros y su desarrollo político interno. China es una experiencia aparte dentro de los países subdesarrollados. Las tendencias recientes parecen insinuar un progresivo aumento de la participación de ese país en las relaciones económicas internacionales aunque, en los plazos históricos previsibles, parece improbable que su gravitación sea comparable al del peso relativo de su población dentro de la población mundial. Las proyecciones clisponibles insinúan que hasta fin de siglo las transacciones internacionales de China no excederían la importancia relativa equivalente de la de los países industrializados de tamaño intermedio.

Dada la multiplicidad de situaciones existentes dentro del Tercer Mundo no es extraño que los países desarrollados pretendan orientar sus políticas sobre bases diferenciadas que tomen en cuenta la situación particular de cada país o grupo de países en desarrollo12. Simultáneamente, se advierte el propósito de ejecutar políticas globales en torno de algunas áreas críticas como la energía, ciertos productos básicos, la explotación de recursos comunes en los mares o el espacio y la preservación del ecosistema. El problema de la pobreza de gran parte del género humano y el destino común del hombre en el planeta, aunque crecientemente reconocido en los centros de podex, no parece inducir acciones significativas de carácter global dentro del futuro previsible. La diferenciación entre políticas diferenciadas y globales vis-a-vis al Tercer Mundo, sumado a Ia dispersión creciente de situaciones nacionales dentro de éste, induce a pensar que la nueva trama de las relaciones económicas internacionales serán cada vez más diferenciadas y complejas. La vieja categoría centro-periferia pierde progresivamente vigencia explicativa porque existen de hecho muchas periferias y algunas dejarán de serlo en plazos relativamente breves. La división internacional del trabajo se transforma permanentemente con las incorporaciones de nuevos bienes y servicios y nuevos partícipes que transforman la posición de cada país dentro del orden económico mundial. Estos cambios en los precios

\footnotetext{
${ }^{2} \mathrm{OCDE}$. Interfutures. L'evolution future des sociétés industrielles en harmonie avec calles des pays en développement. París, 1978.
} 
relativos y en las ventajas comparativas repercuten, a su vez, en la atracción de las inversiones de las corporaciones, en las corrientes financieras, en los flujos tecnológicos y en el número y naturaleza de los agentes económicos que participan en las transacciones internacionales.

En este contexto se comprende que las bases de la solidaridad tercermundista sean más declarativas que reales. No cabe duda que la cooperación horizontal dentro del Tercer Mundo podría tener un efecto trascendente en la promoción del desarrollo de cada país y en la transformación del orden económico internacional. Pero la puesta en práctica efectiva de la cooperación horizontal implica un grado de interferencia y de orientación sobre las fuerzas del mercado y el comportamiento de los agentes económicos que difícilmente pueda concertarse, por lo menos en gran escala, entre los países en desarroIlo. La experiencia latinoamericana, aun en el contexto extremadamente favorable de la común tradición histórica y cultural del área, es suficientemente ilustrativa al respecto. Los vínculos de los países en desarrollo con el resto del mundo seguramente serán más influidos por las tendencias profundas del cambio tecnológico, la transformación de las estructuras productivas y los cambios sociopolíticos que por los esquemas de cooperación a escala internacional. De allí que cada estado nacional continúe siendo el marco fundamental de referencia donde se decide el rumbo de cada país.

\section{e) Limites a la acción de las superpotencias.}

En la introducción a estas notas se hizo referencia a la significación del conflicto entre las superpotencias para la evolución del orden económico internacional. Se señaló allí que las crecientes tensiones internas dentro de los Estados Unidos, la Unión Soviética y los principales aliados de ambas superpotencias se suman a los avances de la tecnología militar para determinar un cuadro incierto en ese campo vital de las relaciones internacionales. Interesa destacar aquí que la tentativa de los centros de poder para alinear a países del Tercer Mundo en sus respectivas zonas de influencia tropieza con obstáculos crecientes. Parece bastante claro que la intervención en los asuntos internos de los países del Tercer Mundo sólo es posible en aquellos de dimensión suficientemente reducida. En estos casos, como en algunas experiencias recientes en Africa, la intervención foránea pueda tener peso relativo suficiente como para influir en la marcha de los acontecimientos. Pero, en los países de mayor dimensión, la intervención debe limitarse a promover la "destabilización" de los gobier- 
nos hostiles o dar apoyo económico y político limitado a los amigos. En los países del Tercer Mundo de dimensión apreciable los conflictos pólíticos expresan predominantemente las tensiones internas de las sociedades nacionales. En tales casos las posibilidades de intervención foránea son limitadas y, como lo revela la experiencia, frecuentemente sus resultados contradicen los objetivos perseguidos. Esto no excluye que los alienamientos políticos internos busquen insertarse en alguno de los campos en pugna dentro del orden internacional. Pero, nuevamente, las opciones internas suelen ser más decisivas en estos casos que la intervención foránea. Las experiencias registradas en la América Latina y en otras regiones, como la muy reciente del Irán, insinúan este carácter dominante de los factores internos en la evolución política de los países del Tercer Mundo. Es este otro aspecto de la dimensión nacional de la experiencia de cada país, sin perjuicio de que los cambios de rumbo o la consolidación del status quo se faciliten o dificulten por la gravitación de los factores externos. De todos modos, cuando las situaciones políticas internas son suficientemente sólidas las posibilidades de interferencia externa son francamente muy limitadas.

La mayor libertad de maniobras potencial de los países del Tercer Mundo frente a los intereses e interferencias de las superpotencias es un aspecto esencial de la dispersión del poder que caracteriza actualmente al sistema internacional. Naturalmente, esto es de la mayor significación en el diseño de las estrategias de clesarrollo y de vinculación internacional de cada país del Tercer Mundo.

\section{CONCLUSIONES}

La desaceleración del crecimiento del comercio mundial, las demandas proteccionistas, los desequilibrios en los pagos internacionales, las fluctuaciones en las paridades de las principales monedas y la inflación, probablemente continuarán imperando en la economía internacional, dentro de los plazos previsibles. Los problemas actuales reflejan tensiones profundas del sistema económico mundial fundadas en los conflictos que imperen en los países centrales, las dificultades en la administración de la interdependencia dentro del Sistema Trilateral, la dispersión del poder económico, las transformaciones dentro del Tercer Mundo y su mayor peso relativo en los acontecimientos internacionales, la repercusión de las tensiones internas de las superpoten. cras y de los avances en la tecnología militar en el conflicto EsteOeste, la dificultad de la economía internacional para asimilar los 
cambios en los precios relativos de la energía y de las manufacturas exportadas desde el Tercer Mundo. Estos iy otros factores explorados en las consideraciones anteriores inducen a pensar que el sistema internacional enfrenta un prolongado período de dificultades.

Uno de los hechos notables de la experiencia contemporánea es que la creciente transnacionalización del sistema mundial coincide con la agudización de los problemas y tensiones internas en la mayor parte de los países. Las dificultades de éstos para responder con eficacia a los nuevos desafíos de su desarrollo económico y social agudiza los desequilibrios del sistema internacional. $\mathrm{X}$ estos desequilibrios, a su vez, complican la gestión de las políticas nacionales. Un ejemplo típico es la incapacidad de los pafses miembros de la ocDe de poner en práctica polfticas concertadas para alcanzar el ajuste de sus pagos internacionales. El temor a la reactivación de las presiones inflacionarias impide que las economías desarrolladas en posición externa más sólida expandan suficientemente su demanda interna para facilitar el ajuste de las economías deficitarias. Un aspecto importante de esta cuestión es el fracaso de las políticas tradicionales, tanto las de inspiración keynesiana como las monetaristas, de compatibilizar el pleno empleo con la estabilidad de precios.

Al mismo tiempo no es previsible que las dificultades actuales concluyan con el derrumbe del orden económico internacional, como ocurrió en la década de 1930. Los mecanismos de control del proceso económico son hoy demasiado poderosos como para permitir una violenta caída de la producción mundial y la ruptura del régimen multilateral de comercio y pagos gestados en los últimos treinta años. Tampoco parece posible que ninguno de los países de cierta dimensión, tanto en el Sistema Trilateral como en el Tercer Mundo, puedan encontrar respuestas válidas a sus problemas fundamentales fuera de sus propias fronteras. Se señaló en el texto que el redespliegue y una nueva división del trabajo sólo son posibles después y no antes de la solución de los problemas básicos que enfrentan hoy las economías desarrolladas. Desde la perspectiva del Tercer Mundo los problemas de subdesarrollo, pobreza extrema y dependencia tampoco pueden ser solucionados desde afuera. Conviene insistir: se trata de una situación paradojal en que cada país asume la responsabilidad fundamental de su propio destino en el marco de un sistema crecientemente transnacionalizado por el impacto del progreso técnico, la multiplicación de agentes económicos que participan en el mercado mundial y, en medida probablemente declinante, por la acción de las grandes corporaciones. 
América Latina enfrenta un contexto externo conflictivo pero también mucho más rico en posibilidades y alternativas. De hecho, las tendencias de largo plazo del sistema mundial están ampliando la libertad de maniobra potencial de los países del área frente al resto del mundo. La dispersión del poder económico internacional, las orientaciones del cambio tecnológico, los límites al gigantismo, la nueva frontera para las pequeñas y medianas empresas y otros factores explorados en las consideraciones anteriores, contribuyen a enriquecer las opciones abiertas a cada país. Las políticas predominantes en los principales países industriales se orientan en el mismo sentido. El debilitamiento de la importancia relativa de la América Latina para los Estados Unidos han inducido en este país nuevos enfoques en sus relaciones con sus vecinos al sur del Río Bravo. La "relación especial" con la América Latina ha terminado y la región es considerada ahora dentro del esquema global de las relaciones externas norteamericanas. Al mismo tiempo, los Estados Unidos diferencian país por país dentro de la región a afectos de diseñar su política. Tanto los Estados Unidos como los otros grandes países industriales se orientan a un tratamiento diferenciado, caso por caso, frente al Tercer Mundo y esto contribuye a hacer aún más compleja la trama de las relaciones internacionales y a ampliar la capacidad de cada país en desarrollo de inducir cambios profundos en sus vínculos con el resto del mundo.

La repercusión de las tendencias contemporáneas de la economía mundial sobre la América Latina está decisivamente condicionada por la situación particular de cada país. También dentro de la region las diferencias son profundas y van en aumento. E1 tamaño de los mercados nacionales, la dotación de recursos naturales, la viabilidad de los sistemas políticos y la estabilidad institucional, la madurez del sistema industrial y de la infraestructura científico-tecnológica, la eficacia del sector público, la capacidad interna de administrar recursos y el desarrollo de las empresas nacionales, son todos factores claves que condicionan el impacto de los acontecimientos externos en cada país de la región. Sea como fuera, las nuevas pautas en la división internacional del trabajo, los cambios en los precios relativos y el cambio tecnológico, están sometiendo a todos los países de la región a fuertes tensiones. Las respuestas a estos desafíos son decisivamente condicionadas por las opciones internas de cada país.

Este carácter interno de las opciones nacionales es facilitado por la "permisividad" del contexto internacional a que se ha hecho referencia persistentemente en estas notas. Aún más, cuando ideologías importadas desde los centros, como en el caso del monetarismo de la 
Escuela de Chicago, influyen decisivamente en el diseño de la política económica de algunos países, no puede decirse que se trate de una "imposición" desde fuera. En tales casos se trata, más bien, de la búsqueda de una racionalidad importada para justificar políticas deseadas por los grupos hegemónicos internos. Es a partir de esta opción interna que ciertas ideologías alcanzan tanta gravitación en algunos países de la región.

La libertad de maniobra frente al contexto externo no quiere decir, ni mucho menos, que los factores externos no influyan en el rumbo de cada país. Se habló antes de la "nacionalización de la dependencia" en el sentido de que importantes sectores de las sociedades latinoamericanas están comprometidos con modelos de desarrollo intimamente asociados a las corporaciones transnacionales, al trasplante de tecnologías, a pautas de consumo de los centros y a otros factores "exógenos". En cierto sentido, la ruptura de los vínculos de dependencia dentro de un modelo tipo enclave es menos compleja que en el marco de economías diversificadas íntimamente ligadas al contexto internacional. Pero aún así, los factores que pueden superar los obstáculos para una inserción externa compatible con el desarrollo de cada país descansan, inevitablemente, en el ámbito interno.

Dadas las tendencias dominantes de la economía internacional contemporánea, la integración latinoamericana vuelve a surgir como un instrumento potencial de gran utilidad para cada uno de los países de la región. Las limitaciones del proceso integracionista en el pasado ha impedido que la dimensión regional alcanzara suficiente masa crítica, como para tener impulso propio y constituir una opción real para los países latinoamericanos. Todas las razones que fundaron al proyecto integracionista desde la década de 1950, y aún más, siguen en pie. La ampliación de los mercados, la profundización de la industrialización y las economías de escala, el fortalecimiento de la posición negociadora externa, la explotación conjunta de recursos compartidos, siguen siendo razones fundamentales que avalan la propuesta integracionista. Pero trasladar estas posibilidades al plano de las decisio. nes políticas constituye todavía una empresa inacabada e incierta. 